\title{
Color stability evaluation of aesthetic restorative materials
}

\section{Adriana Postiglione Bührer Samra(a) \\ Stella Kossatz Pereira ${ }^{(b)}$ \\ Leyla Cotrina Delgado(c) \\ Christiane Phillipini Borges ${ }^{(d)}$}

(a) MSc, Assistant Professor, Discipline of Integrated Clinic; (b) PhD; (c) MSc -

Department of Odontology, State University of Ponta Grossa (UEPG), PR, Brazil.

(d) PhD, Chemistry Department, State University of Ponta Grossa (UEPG), PR, Brazil.
Corresponding author:

Adriana Postiglione Bührer Samra

Rua Ricardo Lustosa Ribas, 167

Ponta Grossa - PR - Brazil

CEP: 84040-140

E-mail: adrianasamra@bol.com.br

Received for publication on Oct 17, 2006

Accepted for publication on Mar 16, 2007

\begin{abstract}
Color match is one of the most important characteristics of aesthetic restorative materials. Maintenance of color throughout the functional lifetime of restorations is important for the durability of treatment. This characteristic is not constant among dental materials. The purpose of this research was to assess the color stability of five aesthetic restorative materials when immersed in a coffee solution. Seventy-one $17 \mathrm{~mm}$ x $1 \mathrm{~mm}$ specimens, divided into five groups, were made using one direct composite resin (Tetric Ceram ${ }^{\circledR}$, Ivoclar/Vivadent - G1), three indirect composite resins (Targis, Ivoclar/Vivadent - G2; Resilab Master, Wilcos - G3; belleGlass ${ }^{\mathrm{TM}} \mathrm{HP}$, Kerr - G4) and one porcelain (IPS Empress $^{\circledast} 2$, Ivoclar/Vivadent - G5). The specimens were immersed in a coffee staining media for 15 days and stored under a controlled temperature of $37^{\circ} \mathrm{C} \pm 1^{\circ} \mathrm{C}$ in the dark. The evaluations were made after 1,7 and 15 days by means of reflectance spectrophotometry. The data was submitted to two-way ANOVA $(\mathrm{p}<0.005)$ and post hoc tests. Statistical difference was observed between G1 / G3 and the other groups; G2 / G4 and the other groups; and G5 and all the other groups. It was concluded that G1 and G3 showed significantly higher discoloration than the other groups. G2 and G4 showed intermediary pigmentation, while G5 showed the smallest changes.
\end{abstract}

Descriptors: Composite resins; Dental porcelain; Pigmentation; Esthetics, dental. 


\section{Introduction}

Color, shape and surface texture are very important in aesthetics, characterizing and personalizing a smile. Even though aesthetic treatments have been one of the most required dental treatments, coming just after pain related treatments, in-depth knowledge of color by dentists has not followed. ${ }^{1}$ Defining aesthetics as "the art of the imperceptible", ${ }^{2}$ color stability can be the difference between success and failure. Burke, Qualtrough ${ }^{3}$ (1994) observed that dental dissatisfaction in $38 \%$ of patients concerns color.

Composite resin discoloration is multifactorial, including factors such as intrinsic discoloration and extrinsic staining. Nevertheless, a correlation between color (discoloration) and conversion rate was established, with incomplete polymerized composite resins showing reduced mechanical properties and greater discoloration susceptibility. ${ }^{4}$

However, since aesthetic restorative materials have different compositions, surface texture and chemical stability, the aim of this study was to evaluate the effect of a coffee solution upon color stability, and to make some considerations about clinical indications and longevity of the restorative materials studied.

\section{Material and Methods}

Five materials were selected and divided into five experimental groups, as described in Chart 1. The choice criterion was that all the materials had different compositions and curing methods. Shade A2 from the Vita Lumin shade guide (Vita ZahnFabrik, Bad Säckingen, Waldshut, Germany) or similar shades from other shade guides were selected, so that the specimens would have a standardized initial color.
Seventy one (71) specimens were made, fifteen for each group, except G5, which had 11 specimens. The sample size was determined by a pilot-test, validating color changes having 1 unit as the starting point.

Specimens were built with $17 \mathrm{~mm}$ in diameter, corresponding to the spectrophotometer sample compartment size and $1 \mathrm{~mm}$ in thickness as required by ISO international standard \#7491:2000. ${ }^{5}$ All materials had their polymerization cycles observed according to the manufacturers' instructions. A piece of dental floss was incorporated to the restorative material. After polymerization, the specimens were finished and polished with sand paper disks. A same operator performed finishing and polishing in a standardized way. G5 specimens received a glaze as recommended by the manufacturer. Once the disks were ready, they were stored for 1 hour in distilled water, in the dark, under a controlled temperature of $37^{\circ} \mathrm{C} \pm 1{ }^{\circ} \mathrm{C}, 6,7$ before color measurement was initiated.

Reflectance spectrophotometry was conducted (Spectrophotometer Varian-Cary 100, Labsphere) with integrating sphere, ${ }^{8,9}$ illuminant D-65, ${ }^{1,10}$ range between 360 and $720 \mathrm{~nm}$, and viewing angle of $10^{\circ} .1$ The measurements were established in mathematic coordinates referred to the international color space CIE-Lab (Commission Internacional de l'Eclairage $L * a * b *)$. CIE-Lab is expressed by the $L *$ coordinate, representing color luminosity, varying from white to black; and the $\mathrm{a}^{*}$ and $\mathrm{b}^{*}$ coordinates, representing the cromaticity of the color, with axes varying from green to red and blue to yellow, respectively. This color space is represented by a sphere, where the $\mathrm{Y}$ axis represents the $L^{*}$ coordinate, the $\mathrm{X}$ axis represents the $\mathrm{b}^{*}$ coordinate and the $\mathrm{Z}$ axis represents

Chart 1 - List of evaluated materials according to type, shade and experimental groups.

\begin{tabular}{|c|c|c|c|c|c|}
\hline Comercial brand & Manufacturer* & Material & Shade & Group & Batch number \\
\hline Tetric Ceram ${ }^{\circledR}$ & Ivoclar / Vivadent & Direct Composite resin micro-hybrid & A2 enamel & G1 & F9519 \\
\hline Targis & Ivoclar / Vivadent & Second Generation Indirect Composite Resin & Cor 130 dentin & G2 & N54820 \\
\hline Resilab Master & Wilcos & Second Generation Indirect Composite Resin & E-11 enamel & G3 & $019 / 03$ \\
\hline belleGlass $^{\mathrm{TM}} \mathrm{HP}$ & Kerr & Second Generation Indirect Composite Resin & Cor A2 dentin & G4 & 204D32 \\
\hline IPS-Empress 2 & Ivoclar / Vivadent & Porcelain & 130 dentin & G5 & N553946 \\
\hline
\end{tabular}

* Ivoclar/Vivadent: Schaan, Lichtenstein; Wilcos do Brasil: Petrópolis, RJ, Brazil; Kerr: Orange, CA, USA. 
the $\mathrm{a}^{*}$ coordinate. The match of these coordinates results in a spatial position that mathematically expresses a color.

After initial measurement, the specimens were immersed in a coffee solution (Café Lontrinha ${ }^{\circledR}$, Ponta Grossa, PR, Brazil), with the dental floss preventing contact with the bottom of the container, and they were kept under a controlled temperature of $37^{\circ} \mathrm{C} \pm 1^{\circ} \mathrm{C} .{ }^{7,10}$ The coffee solution was prepared by using $25 \mathrm{~g}$ of powder for $250 \mathrm{ml}$ of water, standardized and changed every 2 days. ${ }^{5,11}$ The evaluations were made at baseline, 1 day, 7 days and 15 days after immersion in the staining media. The distance between the initial spatial position (the initial match of L*a*b* coordinates), and the spatial position obtained in each measurement, (the updated match of $L * a * b *$ coordinates) represented the discoloration of the specimen, or $\Delta \mathrm{E}$. Before the readings, the specimens were washed in running water for 1 minute and brushed with new soft dental brushes (Sorriso-Kolynos Original, Colgate-Palmolive Company, São Bernardo do Campo, SP, Brasil).

A scale for $\Delta \mathrm{E}$ evaluation ${ }^{12,13}$ was used. This scale considers non-visible the difference $(\Delta \mathrm{E})$ smaller or equal than 1 unit, visually perceptible to the experienced examiner between 1 and 2 units, and the boundary between clinically acceptable and unacceptable at 3.3 units.
Statistical analyses were performed in two stages. Initially, the dependent variables delta $\mathrm{L}^{*}\left(\Delta \mathrm{L}^{*}\right)$, delta $a^{*}\left(\Delta a^{*}\right)$ and delta $b *\left(\Delta b^{*}\right)$ were considered. After that, the variable delta $\mathrm{E}(\Delta \mathrm{E})$ was taken into account. All of them were related to the independent variables time and experimental group, using the two-way ANOVA test. If the null hypothesis was rejected ( $\mathrm{p} \leq 0.05)$, post hoc comparison was made using the Tukey test.

\section{Results}

Two-way ANOVA tests were performed for $\Delta \mathrm{L}^{*}$, $\Delta \mathrm{a}^{*}$ and $\Delta \mathrm{b}^{*}$, separately, and correlated to experimental group and time, resulting in $\mathrm{p}<0.005$ for the three variables analyzed.

Concerning the variable delta $L^{*}$, there were statistical differences between G1 and G4 ( $p<0.001)$, G1 and G2 (p = 0.001), G1 and G5 (p < 0.001), G2 and G5 (p = 0.037), G3 and G4 ( $\mathrm{p}=0.016)$, and G3 and G5 $(\mathrm{p}<0.001)$. This $\Delta \mathrm{L}^{*}$ difference was the most significant one of all groups, except for Groups 3 and 5 , as shown in Table 1 . Concerning the time factor, there were significant statistical differences in $\Delta \mathrm{L}^{*}$ values among the time periods $(\mathrm{p}<0.005)$.

When the $\Delta \mathrm{a} *$ variable was analyzed, there were significant differences among G1 and the other groups ( $\mathrm{p}<0.001)$, between G5 and G3 ( $\mathrm{p}<0.004)$, and between G5 and G4 ( $\mathrm{p}<0.002)$, as presented in

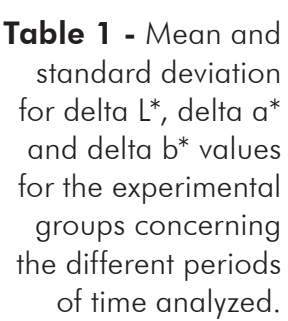

Table 1 - Mean and
standard deviation
for delta $L^{*}$, delta $a^{*}$
and delta $b^{*}$ values
for the experimental
groups concerning
the different periods
of time analyzed.

\begin{tabular}{l|c|c|c|c|c|c}
\hline Time/ Group & Tetric Ceram & Targis & Resilab Master & belleGlass $^{\text {TM }}$-HP & IPS-Empress $^{\circledR 2}$ & $*$ \\
\hline$\Delta \mathrm{L}^{*} 1$ day & $-3.05(1.16)$ & $-1.53(0.70)$ & $-1.56(0.46)$ & $-1.04(0.99)$ & $-0.17(0.80)$ & $\mathrm{A}$ \\
\hline$\Delta \mathrm{L}^{*} 7$ days & $-5.49(1.23)$ & $-3.03(1.19)$ & $-4.01(1.20)$ & $-2.52(1.16)$ & $-0.27(1.07)$ & $\mathrm{B}$ \\
\hline$\Delta \mathrm{L}^{*} 15$ days & $-7.44(1.31)$ & $-3.59(0.92)$ & $-5.29(0.83)$ & $-2.59(0.81)$ & $-0.29(1.24)$ & $\mathrm{C}$ \\
\hline$* *$ & $\mathrm{D}$ & $\mathrm{BC}$ & $\mathrm{CD}$ & $\mathrm{AB}$ & $\mathrm{A}$ & \\
\hline$\Delta \mathrm{a}^{*} 1$ day & $1.25(0.15)$ & $0.53(0.18)$ & $0.36(0.19)$ & $0.86(0.34)$ & $0.12(0.11)$ & $\mathrm{A}$ \\
\hline$\Delta \mathrm{a}^{*} 7$ days & $2.04(0.25)$ & $0.50(0.32)$ & $0.95(0.25)$ & $0.96(0.37)$ & $0.08(0.14)$ & $\mathrm{B}$ \\
\hline$\Delta \mathrm{a}^{*} 15$ days & $2.50(0.30)$ & $0.44(0.38)$ & $1.30(0.24)$ & $1.18(0.28)$ & $0.13(0.19)$ & $\mathrm{B}$ \\
\hline$* *$ & $\mathrm{C}$ & $\mathrm{BA}$ & $\mathrm{B}$ & $\mathrm{B}$ & $\mathrm{A}$ & \\
\hline$\Delta \mathrm{b}^{*} 1$ day & $2.13(0.70)$ & $-0.31(0.80)$ & $3.72(0.67)$ & $0.64(0.96)$ & $0.32(0.53)$ & $\mathrm{A}$ \\
\hline$\Delta \mathrm{b}^{*} 7$ days & $2.52(1.06)$ & $-0.45(1.15)$ & $5.90(0.79)$ & $0.70(0.44)$ & $-0.31(0.63)$ & $\mathrm{A}$ \\
\hline$\Delta \mathrm{b}^{*} 15$ days & $2.60(1.08)$ & $-0.20(1.26)$ & $6.94(0.88)$ & $0.87(0.57)$ & $-0.26(0.74)$ & $\mathrm{A}$ \\
\hline$* *$ & $\mathrm{C}$ & $\mathrm{A}$ & $\mathrm{D}$ & $\mathrm{B}$ & $\mathrm{AB}$ & \\
\hline
\end{tabular}

Different letters refer to statistical differences among results in the post hoc Tukey test: ${ }^{*}$ comparison among time periods; ${ }^{* *}$ comparison among groups. 
Table 2 - Mean and standard deviation of delta $E$ values related to previous time concerning the Experimental Groups in the different periods of time evaluated.

\begin{tabular}{l|c|c|c|c}
\hline \multicolumn{1}{c|}{ Group } & Initial - 1 day & 1 day - 7 days & 7 days - 15 days & $* *$ \\
\hline Tetric Ceram & $4.042(0.964)$ & $2.734(1.394)$ & $2.156(0.571)$ & B \\
\hline Targis & $1.863(0.609)$ & $1.823(0.865)$ & $0.795(0.226)$ & $\mathrm{A}$ \\
\hline Resilab Master & $4.087(0.671)$ & $3.461(0.955)$ & $2.162(0.822)$ & $\mathrm{B}$ \\
\hline belleGlass $^{\text {Tu }} \mathrm{HP}$ & $2.368(0.936)$ & $1.972(1.052)$ & $1.116(0.781)$ & $\mathrm{A}$ \\
\hline IPS-Empress $2^{\circledR}$ & $0.934(0.398)$ & $1.329(0.635)$ & $0.951(0.624)$ & $\mathrm{A}$ \\
\hline$*$ & $\mathrm{~B}$ & $\mathrm{~B}$ & $\mathrm{~A}$ & \\
\hline
\end{tabular}

Different letters refer to statistical differences among results in the post hoc Tukey test: ${ }^{*}$ comparison among time periods; ${ }^{* *}$ comparison among groups.
Table 3 - Mean and standard deviation of delta $E$ values related to the baseline concerning the Experimental Groups in the different periods of time evaluated.

\begin{tabular}{l|c|c|c|c}
\hline \multicolumn{1}{c|}{ Group } & $\begin{array}{c}\text { Initial }- \\
\text { lday }\end{array}$ & $\begin{array}{c}\text { Initial - } \\
7 \text { days }\end{array}$ & $\begin{array}{c}\text { Initial }- \\
15 \text { days }\end{array}$ & $* *$ \\
\hline Tetric Ceram & $4.04(0.96)$ & $7.45(1.28)$ & $8.34(1.23)$ & C \\
\hline Targis & $1.86(0.60)$ & $3.33(1.15)$ & $3.85(0.87)$ & B \\
\hline Resilab Master & $4.08(0.67)$ & $7.29(0.92)$ & $8.86(0.94)$ & C \\
\hline belleGlass $^{\text {TM }}$ HP & $2.36(0.93)$ & $2.93(0.91)$ & $3.40(0.58)$ & B \\
\hline IPS-Empress $^{\circledR} 2$ & $0.93(0.39)$ & $1.15(0.56)$ & $1.28(0.73)$ & A \\
\hline$*$ & A & B & B & \\
\hline
\end{tabular}

Different letters refer to statistical differences among results in the post hoc Tukey test: ${ }^{*}$ comparison among time periods; ${ }^{* *}$ comparison among groups.

Table 1. Considering the variable time, there were significant statistical differences in $\Delta \mathrm{a}^{*}$ values between the periods 1 day and 7 days $(p=0.02)$, and 1 day and 15 days $(\mathrm{p}<0.001)$, as can be seen in Table 1 . Concerning the variable $\Delta \mathrm{b}^{*}$, there were significant differences among G3 and the other groups $(\mathrm{p}<0.001), \mathrm{G} 1$ and the other groups $(\mathrm{p}<0.001)$, and between G2 and G4 ( $\mathrm{p}<0.002)$.

Total color difference $(\Delta \mathrm{E})$ was evaluated in relation to previous time and to baseline (initial measurement), considering the experimental group and time factors, using two-way ANOVA, resulting in $\mathrm{p}<0.001$ for both factors and for the interaction of both. Considering $\Delta \mathrm{E}$ in relation to previous time, there were no significant statistical differences among G2, G4 and G5, neither between G1 and G3, with these groups showing $\Delta \mathrm{E}^{*}$ mean values statistically higher than those of G2, G4 and G5 $(\mathrm{p}<0.001)$. Therefore, G1 and G3 showed the highest values of $\Delta \mathrm{E}^{*}$ within the evaluated materials. Ta- ble 2 demonstrates that the rate of discoloration was proportional to the rate of $\Delta \mathrm{E}^{*}$ difference between the materials.

Considering the time factor, the period corresponding to 7-15 days showed significant statistical difference from the other periods $(\mathrm{p}<0.002)$, with the lowest mean $\Delta \mathrm{E}^{*}$ values. Thus, the highest $\Delta \mathrm{E}$ values were observed in the initial-1 day and 1 day- 7 days periods (Table 2).

As regards total color difference $(\Delta \mathrm{E})$ values related to baseline, groups G1 and G3 were statisticaly different from groups G2 and G4 ( $<<0.001$ ), and group G5 was statistically different from the other groups ( $\mathrm{p}=0.002)$, as can be seen in Table 3 .

\section{Discussion}

Discoloration occurred in Groups 1, 2, 3 and 4 in the same way, the specimens became darker (decrease of $L^{*}$ ) and reddish (increase of values of $\mathrm{a}^{*}$ ). These results match those of Schulze et al. ${ }^{14}$ (2003), with the same kind of discoloration.

Concerning $\Delta \mathrm{L}^{*}$, it is important to emphasize that the $\mathrm{L}^{*}$ coordinate represents luminosity, and the human eye perceives this color characteristic more clearly, since the quantity of cells (rods) responsible for black and white vision is much higher than that of cells responsible for colored vision (cones). So, any loss in luminosity is critical to color stability and to clinical success.

The discoloration occurring from a coffee solution is mostly due to extrinsic discoloration, but intrinsic discoloration may exist. Extrinsic factors included adsorption and absorption of pigments. ${ }^{15,16}$ Coffee pigmentation originates from both mechanisms of adsorption of colorant on the surface and 
absorption in the sub-surface layer, ${ }^{17}$ probably related to the compatibility of the polymeric phase of the composite resin with yellow colorants present in coffee, ${ }^{18}$ which could explain the increase in values of the $\mathrm{b} *$ coordinate tending to yellow.

The efficiency of polymerization may influence discoloration, since the higher degree of conversion, the smaller the amount of residual monomers available to form colored degraded products. Complementary polymerization performed through light and heat (Targis) and through heat, pressure and vacuum (belleGlass ${ }^{\mathrm{TM}}$ ) increase significantly the conversion rate of both materials, respectively by $80 \%$ and $98.5 \%$, according to the manufacturers' data, which are in agreement with our results. Some studies ${ }^{19,20}$ point to a significant rise in the conversion rate, microhardness, texture smoothness, flexure resistance and, as a consequence, color stability when a second cycle of polymerization is performed. Figueiredo ${ }^{21}$ (1999) describes enhanced physical properties, including color stability, when heat is incorporated to additional polymerization of composite resins. This additional polymerization may produce a loosening on the tension existing in interface matrix/filler particles, responsible for subsurface layer degradation, making microcracks and gaps appear more easily, thus acting as an entrance for discoloration. ${ }^{17}$ Leinfelder $^{22}$ (1997) refers to heat, pressure and vacuum as factors contributing to polymerization efficiency. The results obtained with Targis and belleGlass ${ }^{\mathrm{TM}}$ showed a color change significantly smaller than that obtained with Tetric Ceram $^{\circledR}$ and Resilab Master, which do not use any complementary polymerization. On the other hand, studies conducted by Dietschi et al. ${ }^{17}$ (1994) and Fonseca et al. ${ }^{19}$ (2002) demonstrated that additional polymerization is not efficient for all materials and can be compensated by cross-linking reactions extending for one week after initial photoactivation. The addition of multifunctional monomers may modify the polymerization reaction, increasing the kinetics of the cross linking process in second generation indirect composite resins.

Considering material composition correlated to total color difference, it was noted that Tetric Ce$\mathrm{ram}^{\circledR}$ and Resilab Master showed no statistical dif- ference between each other, exhibiting the biggest $\Delta \mathrm{E}$ values. However, composite resin Tetric Ceram had demonstrated the best color stability in previous studies, when it was compared to other direct restorative materials, ${ }^{13,15}$ confirming the superiority of second generation indirect composites, in consonance to previous studies. ${ }^{12,23}$

Nevertheless, second generation composite resins have demonstrated different behaviors among them, not allowing a generic answer to color stability, which could explain the contradictory results obtained in previous studies. ${ }^{12,22}$ It was noted that the two sub-microhybrid composites, with high filler content, between $75 \%$ and $85 \%$, with additional polymerization, Targis and belleGlass ${ }^{\mathrm{TM}} \mathrm{HP}$, displayed the best results. Moreover, the indirect resin Resilab Master, hybrid of thin particles (53\% filler) and with conventional photopolymerization, presented the worst discoloration.

The color change results revealed that Tetric Ce$\operatorname{ram}(\Delta \mathrm{E}=8.34)$ and Resilab Master $(\Delta \mathrm{E}=8.86)$ were clinically unacceptable, with $\Delta \mathrm{Es}$ higher than the maximum limit $\Delta \mathrm{E}=4.4,{ }^{17}$ or $\Delta \mathrm{E}=3.7,{ }^{12}$ or even the most commonly acceptable $\Delta \mathrm{E}=3.3 .^{18}$ The indirect composites Targis $(\Delta \mathrm{E}=3.85)$ and belleGlass ${ }^{\text {TM }} \mathrm{HP}$ $(\Delta \mathrm{E}=3.40)$ could be considered clinically acceptable because even though their results were beyond the commonly known boundary, they were still below the maximum limit cited by Dietschi et al. ${ }^{17}$ (1994) after 15 days of experimental treatment.

It is important to emphasize the impossibility of establishing the exact correlation between in vitro and in vivo tests, since the oral environment cannot be reproduced in the laboratory, and restorative materials are never subjected to staining medias for such a long period of time. ${ }^{24}$ Previous studies ${ }^{6,21,24}$ demonstrated that the highest discoloration occurred during the period of 1 day to 7 days, extending for 14 days, when it tended towards saturation. ${ }^{18}$

Finally, knowing the restorative material's composition is important, as is respecting its polymerization cycle, and promoting adequate surface texture in order to select the appropriate material for each clinical application, and use it in a competent way to obtain its best properties, thus guaranteeing longevity and success. 


\section{Conclusion}

The restorative materials studied behaved in different ways. Composite resin Tetric Ceram ${ }^{\circledR}$ (Ivoclar/Vivadent) and indirect resin Resilab Master (Wilcos) showed significantly higher discoloration than indirect resins Targis (Ivoclar/Vivadent) and belleGlass ${ }^{\text {Tix }} \mathrm{HP}$ (Kerr) which showed intermediary values, while porcelain IPS-Empress ${ }^{\circledR} 2$ (Ivoclar/ Vivadent) displayed the lowest discoloration at the end of the experimental period. It was observed that the coffee contact period was relevant, with the

\section{References}

1. Al-Wahadni A, Ajlouni R, Al-Omari Q, Cobb D, Dawson D. Shade-match perception of porcelain-fused-to-metal restorations: a comparison between dentist and patient. J Am Dent Assoc. 2002;133(9):1220-5; quiz 1260-1.

2. Mendes WB, Paula E, Bonfante G. Seleção de Cores sem Mistério. In: Gonçalves EANG, Feller C. Atualização na clínica odontológica: a prática na clínica geral. São Paulo: Artes Médicas; 1998. p. 100-20.

3. Burke FJT, Qualtrough AJE. Aesthetic inlays: composite or ceramic? Br Dent J. 1994;176(2):53-60.

4. Micali B, Basting RT. Effectiveness of composite resin polymerization using light-emitting diodes (LEDs) or halogen-based light-curing units. Braz Oral Res. 2004;18(3):266-70.

5. International Organization for Standardization. ISO 7491:2000 (E), Dental Materials - Determination of color stability. [cited 2003 Nov 22]. Available from: http://www. webstore.ansi.org.

6. Dinelli W, Cândido MS, Saad JRC, Oliveira OBJ, Loffredo LCM. Estudo da influência da retenção de corantes na translucidez de resinas compostas: efeito de materiais, tempo e meios de imersão. Rev ABO Nac. 1995;2(6):422-7.

7. Miyagawa Y, Powers JM, O’Brien WJ. Optical properties of direct restorative materials. J Dent Res. 1981;60(5):890-4.

8. Kolbeck C, Rosentritt M, Lang R, Handel G. Discoloration of facing and restorative composites by UV-irradiation and staining food. Dent Mater. 2006;22(1):63-8.

9. Lu H, Roeder LB, Lei L, Powers JM. Effect of surface roughness on stain resistance of dental resin composites. J Esthet Restor Dent. 2005;17(2):102-8; discussion 109.

10. Paravina RD, Ontiveros JC, Powers JM. Curing-Dependent Changes in color and translucency parameters of composite bleach shades. J Esthet Restor Dent. 2002;14(3):158-66.

11. Kuehni R, Marcus RT. An experiment in visual scaling of small color differences. Color Res Appl. 1979;4(2):83-91.

12. Douglas RD. Color Stability of new-generation indirect resins for prosthodontic application. J Prosthet Dent. 2000;83(2):16670 . greatest discoloration occurring between 1 day and 7 days, although it continued to increase until the end of the experimental period.

\section{Acknowledgements}

This study was supported by the Araucaria Foundation. G2 specimens were manufactured by Laboratório Calgaro, G3, by Atelier de Prótese Dentária Nunes \& Correia, while G4 and G5, by Laboratório Romanini.

13. Vichi A, Ferrari M, Davidson CL. Color and opacity variations in three different resin-based composite products after water aging. Dent Mater. 2004;20(6):530-4.

14. Schulze KA, Marschall SJ, Gansky SA, Marschall GW. Color stability and hardness in dental composites after accelerated aging. Dent Mater. 2003;19(7):612-9.

15. Iazzetti G, Burgess JO, Gardiner D, Ripps A. Color stability of fluoride-containing restorative materials. Oper Dent. 2000;25(6):520-5.

16. Rosentritt M, Esch J, Behr M, Leibrock A, Handel J. In vivo color stability of resin composite veneers and acrylic resin teeth in removal partial dentures. Quintessence Int. 1998;29(8):51721.

17. Dietschi D, Campanile G, Holz J, Meyer JM. Comparison of the color stability of ten new-generation composites: an in vitro study. Dent Mater. 1994;10(6):353-62.

18. Um CM, Ruyter IE. Staining of resin-based veneering materials with coffee and tea. Quintessence Int. 1991;22(5):377-86.

19. Fonseca RB, Pizzi ECG, Fernandes AJN, Martins LRM. Propriedades mecânicas de compósitos polimerizados adicionalmente por vários métodos. Pesqui Odontol Bras. 2002;16(supl):244.

20. Kakaboura A, Rahiotis C, Zinelis S, Al-Dhamadi YA, Silikas $\mathrm{N}$, Watts DC. In vitro characterization of two laboratoryprocessed resin composites. Dent Mater. 2003;19(5):393-8.

21. Figueiredo JLG. Estudo espectrofotométrico da estabilidade de cor de três resinas e uma cerâmica em contato com café [Dissertação de Mestrado]. São Paulo: Universidade de São Paulo; 1999.

22. Leinfelder K. New developments in resin restorative systems. J Am Dent Assoc. 1997;128(5):573-81.

23. Ghulman M, Nathanson D. Effect of accelerated aging on color stability of indirect resin composites. [cited $2003 \mathrm{Dez}$ 23]. Available from: http://iadr.confex.com/iadr/2003Goteborg/techprogram/abstract_32984.htm.

24. Wiltshire WA, Labuschagne PW. Staining of light-cured aesthetic resin restorative materials by different staining media: an in vitro study. J Dent Assoc S Afr. 1990;45(12):561-5. 